\title{
Treatment Planning Optimization in Radiotherapy Using the Bolus
}

\author{
ANCA MUNTEANU ${ }^{1,2}$, FLORINA DANIELA IVAN ${ }^{3,4}$, ALEXANDRU PATRASCU1,5*, VERA BALAN ${ }^{4}$, CATALINA URSACHE², \\ LILIANA VERESTIUC ${ }^{4}$ \\ ${ }^{1}$ Grigore T.Popa University of Medicine and Pharmacy lasi, Faculty of Medicine, Department of Medical Oncology-Radiotherapy, \\ 16 Universitatii Str., 700115, lasi, Romania \\ ${ }^{2}$ Regional Institute of Oncology, Department of Radiotherapy, 2-4 General Henry Mathias Berthelot Str., 700483, Iasi, Romania \\ ${ }^{3}$ Gheorghe Asachi Tehnical University of Iai, Faculty of Chemical Engineering and Environmental Protection, 67 Dimitrie \\ Mangeron Blvd. 7000050, Iasi, Romania \\ ${ }^{4}$ Grigore T.Popa University of Medicine and Pharmacy lasi, Faculty of Medical Bioengineering, 9-13 Mihail Kogalniceanu Str., \\ 700454, lasi, Romania \\ ${ }^{5}$ Clinical Recovery Hospital, 12-14 Pantelimon Halipa Str.,700614, Iasi, Romania
}

The present paper presents the results of the research regarding the bolus structure (Bio-Rad Win-IR instrument), the elasticity modulus, the bioadhesiveness properties (TA-XT2 Plus analyzer) and the clinical applications of the bolus in the adjuvant irradiation after radical mastectomy (Treatment Plan System Eclipse). The dose-volume histogram has made a comparative evaluation for with and without bolus treatment plans and confirmed the importance of bolus utilisation in selected patients. Conclusions: the thickness of the applied bolus is dependent on the skin dose required, on the treatment technique and must be equal to the depth of the build-up region for the removal of the skin-sparing effect of a high energy radiation.

Keywords: radiotherapy, planning, bioadhesive, bolus, histogram

Achieving a treatment plan that respects both the homogeneous distribution of the prescribed dose in the target volume and the dose constraints for adjacent risk organs requires choosing the appropriate irradiation technique, butin some cases, it also requires the application of a bolus to the surface of the irradiated volume.

The irradiation of the chest wall after radical mastectomy often requires the application of a bolus to obtain the optimal parameters of the treatment plan. The type and thickness of the bolus must be included in the calculation algorithm [1, 2].

The bolus allows irradiation of the skin with $100 \%$ of the prescribed dose, while without the bolus, the skin (in which almost all local relapses occur in breast cancer [3-9]) receives about $70 \%$ of the prescribed dose, and the nontarget tissues (muscles, ribs) receive $100 \%$ of the dose. Similarly, the bolus is indicated for irradiation of laryngeal tumors with extension at the anterior commissure or primary vulvar tumors $[6,7]$.

Depending on the total dose irradiation and dose fractionation, when the bolus is used, the late cutaneous atrophy may occur more frequently.

\section{Experimental part}

Materials and methods

Structure

ATR-IR spectrum was measured using a Bio-Rad WinIR instrument with the range of 4000 to $400 \mathrm{~cm}^{-1}$ in the ATR mode: mono reflection device, using a diamond crystal with incidence angle of $45^{\circ}$.

\section{Elasticity modulus measurements}

The texture analyzer TA-XT2 Plus (Stable micro systems UK) was used for testing the elasticity of the gel, by using a cylinder of $12 \mathrm{~mm}$ diameter and compression speeds of $1 \mathrm{~mm} / \mathrm{s}$. The slopes from the stress-strain curves at 50\% deformations were used to calculate an apparent compression modulus. Ten samples were measured; the samples height was of $9.4 \mathrm{~mm}$ and their area was between $95 \mathrm{~mm}^{2}$ and $105 \mathrm{~mm}^{2}$. An initial fast deformation of $50 \%$ at $1 \mathrm{~mm} / \mathrm{s}$ was kept constant for $60 \mathrm{~s}$.

\section{Bioadhesive properties}

The same texture analyzer TA-XT2 (Stable micro systems UK) was used for testing the adhesive properties of the material. The efficiency of the gel adhesion $(8 \mathrm{~mm}$ diameter; $2 \mathrm{~mm}$ height) on to a chicken fresh skin (cleaned with diluted SDS solution $(0.1 \%, \mathrm{w} / \mathrm{vol})$ and rinsed with distilled water, wiped with filter paper to remove the water) was evaluated at room temperature. The texture analyser has a moving arm, a cylinder probe, a heavy duty platform and a holed plate. The sample is attached to the probe which is then pressed on to the receiving surface until the trigger force is detected. The gel samples were attached to the probe in such a way that the probe was fully covered so as to avoid any errors due to interaction. The biological tissue was used as a receiver and placed between the platform and the plate. $1 \mathrm{ml}$ of phosphate buffer was introduced into the formed inlet above the membrane. This was repeated eight times. The work of adhesion (TWA) and the maximum detachment force (MDF) were recorded.

The settings of the texture analyser were (table 1):

\begin{tabular}{|c|c|}
\hline Parameters & Value \\
\hline Pre-test speed & $1 \mathrm{~mm} / \mathrm{s}$ \\
\hline Post-test speed & $20 \mathrm{~mm} / \mathrm{s}$ \\
\hline Applied force & $2.0 \mathrm{kgf}$ \\
\hline Return distance & $20 \mathrm{~mm}$ \\
\hline Contact time & 60 seconds \\
\hline Trigger force & $0.1 \mathrm{kgf}$ \\
\hline
\end{tabular}

Table 1

THE SETTINGS OF THE PARAMETERS

*email: patrascu_alex@yahoo.com 


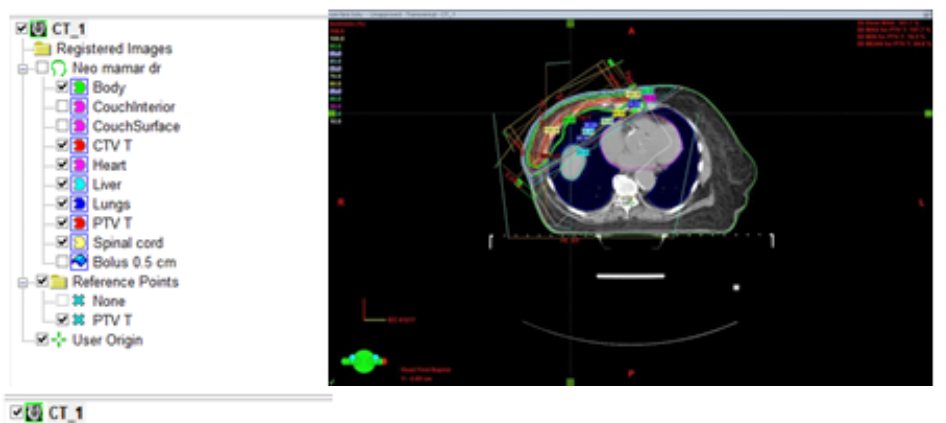

Fig.1. The treatment plan without bolus

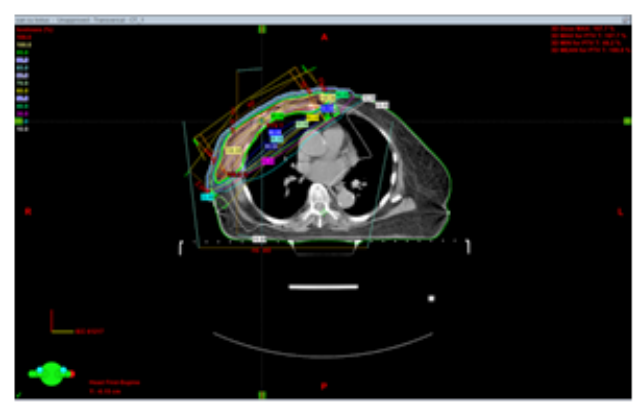

Fig.2. The treatment plan with bolus

The steps of the radiotherapy planning were: CT simulation using a SOMATOM DEFINITION scanner, delineation of target volumes and organs at risk, dosimetry and determination of treatment parameters through the Eclipse treatment plan system.

The treatment plan for irradiation of the right chest wall was initially performed without bolus (fig. 1) and subsequently with a bolus of $0.5 \mathrm{~cm}$, marked with blue (fig. 2). The total dose of irradiation in the target volume (PTV) was 42.56Gy, divided in 16 fractions, 2.66Gy per fraction. The organs at risk are the lungs, the liver, the heart and the spinal cord (fig. 1, 2).

\section{Results and discussions}

The bolus material is made of non-toxic components and it usually is transparent. High dose irradiation should have no effect on the appearance and property of the gel pad.

The ATR -FTIR data registered for the studies bolus material are presented in figure 3.

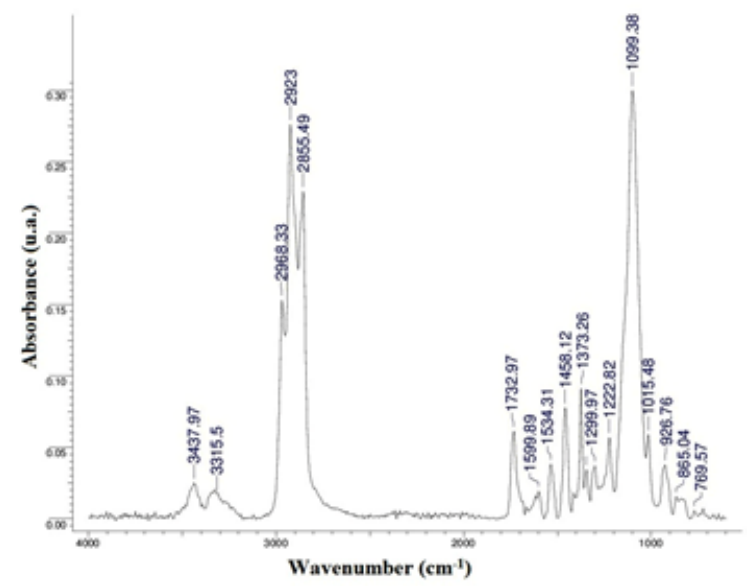

Fig.3. ATR-FTIR spectrum for the gel

The peaks at 2968,2923 and $2855 \mathrm{~cm}^{-1}$ respectively, are the asymmetric and symmetric stretching vibration $v(\mathrm{CH} 2)$, indicating an important content of the aliphatic groups. The characteristic stretching vibration, which peaks at $1732 \mathrm{~cm}^{-1}$, belongs to the carbonyl groups of the polyester chains. The peaks at $1599 \mathrm{~cm}^{-1}$ belong to the stretching vibrations $v(C=C)$ of the aromatic cycles and the peaks at the 1534 and $1222 \mathrm{~cm}^{-1}$ respectively, 1599, $865 \mathrm{~cm}^{-1}$ - due to the double bonds $\mathrm{CH}=\mathrm{CH}, 1373 \mathrm{~cm}^{-1}$ - due to the bending vibration $v(-\mathrm{CH}), 1099 \mathrm{~cm}^{-1}$ - due to hydroxyl groups. The bolus material characteristics are presented in table 2 .

Table 2

BOLUS MATERIAL CHARACTERISTICS

\begin{tabular}{|c|c|c|c|}
\hline $\begin{array}{c}\text { Bolus } \\
\text { materials }\end{array}$ & $\begin{array}{l}\text { Density } \\
{\left[\mathrm{g} / \mathrm{cm}^{3}\right]}\end{array}$ & $\begin{array}{c}\text { Optical } \\
\text { characteristics }\end{array}$ & $\begin{array}{c}\text { Elasticity } \\
\text { modulus }[\mathrm{MPa}]\end{array}$ \\
\hline SuperFlab & 1.07 & Transparent & 37 \\
\hline
\end{tabular}

The bolus material is transparent with a density of 1.07 $\mathrm{g} / \mathrm{cm}^{3}$ and the elasticity modulus indicates a good flexibility. A good transparency is necessary to observe the skin surface of the patient and markings on the patient through the bolus material. Also, the material clarity provides a benefit to the radiation oncologist who uses the bolus material for radiation therapy in the skin surface treatment [8]. The Young modulus dictates the material softness and draping properties and very high values are not recommended $[9,10]$.

The adhesive nature of the bolus material is a very important characteristic because a material such as this one shoud provide excellent skin contact without air gaps. Decreasing tackiness levels can correlate with decreased drapeability. While the bolus material should not be too tacky, the elimination of tackiness from the bolus material generally should not sacrifice drapeability.

The adhesion of polymers is the result of physical entanglement which promotes secondary chemical bonding, mainly $\mathrm{H}$-bonding and van der Waals attraction. These forces are related to the chemical structure of the polymers. The types of surface chemical groups of adhesive polymers that contribute to adhesion include hydroxyl, carboxyl, amine and amide groups in the structure. Polymer characteristics which are necessary for adhesion are (a) strong $\mathrm{H}$-bonding groups, (b) strong anionic charges, (c) high molecular weight, (d) sufficient chain flexibility, and (e) surface energy properties [11]. On a surface, the unsatisfied bonding potential of molecules is different from the bulk material where the interactions are uniform in the all directions. On the surface, a free energy is produced and the molecules will try to reduce this free energy by interacting with molecules in an adjacent phase, therefore the adhesion properties are manifested. The values for the maximum detachment 
force (MDF) and work of adhesion (TWA) are specific for materials in contact with the skin (fig. 4).

Analysis of dose distribution in target volume and risk organs, initially performed separately for with bolus and without bolus treatment plan (fig. 5, 6, table 3, 4), then comparative (fig. 7, table 5) indicates compliance with the mandatory condition of inclusion in $95 \%$ isodose of at least $95 \%$ of PTV for bolus treatment plan only, under the conditions of conformity to dose constraints for organs at risk (similar doses to lungs, liver, heart, spinal cord).

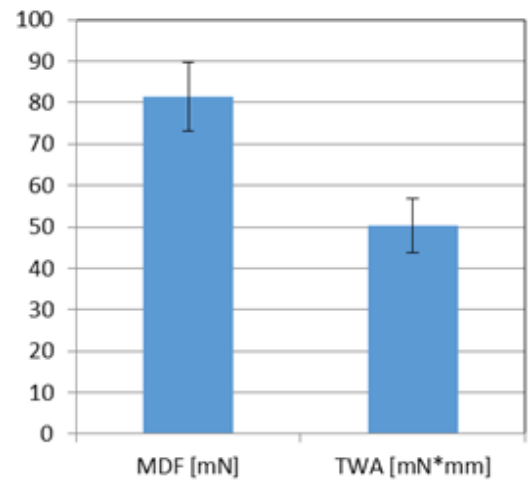

Fig.4.Maximum detachment force (MDF) and work of adhesion (TWA) for the tested bolus material

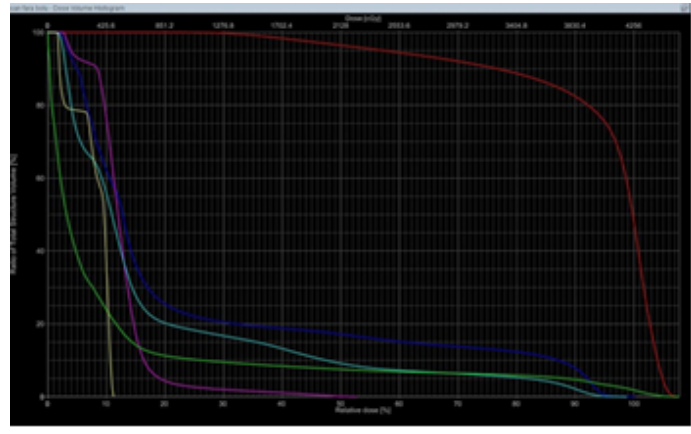

Fig.5. Dose-volume histogram without bolus

Table 3

DOSE DISTRIBUTION WITHOUT BOLUS
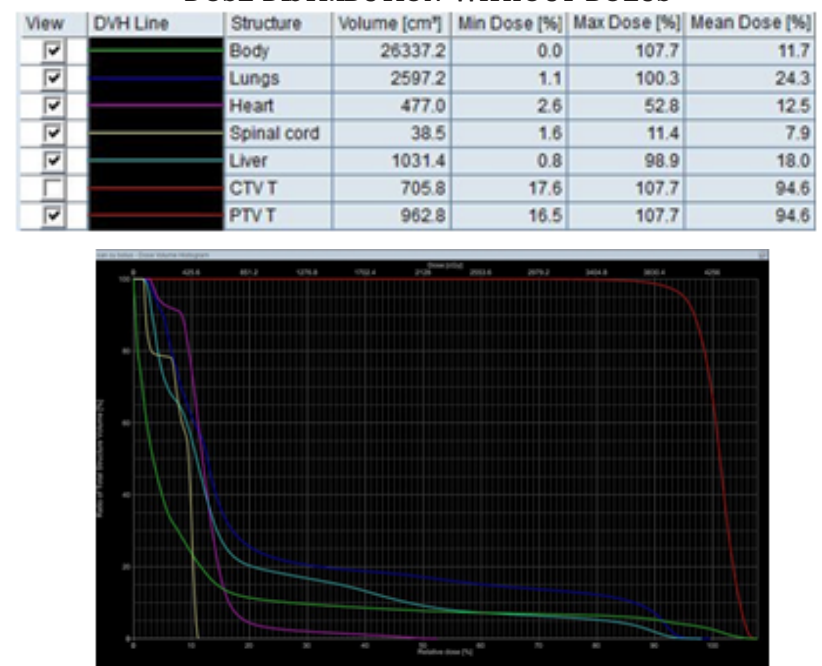

Fig.6. Dose-volume histogram with bolus

Table 4

DOSE DISTRIBUTION WITH BOLUS

\begin{tabular}{|c|c|c|c|c|c|c|}
\hline new & DVH Line & Structure & Volume $\left[\mathrm{cm}^{\prime}\right]$ & Min Dose [\%] & Uax Dose [\%] & Mean Dose [\%] \\
\hline F & & Body & 26337.2 & 0.0 & 107.7 & 12.1 \\
\hline $\bar{\nabla}$ & & Lungs & 2597.2 & 1.1 & 99.6 & 24.1 \\
\hline $\bar{\nabla}$ & & Heant & 477.0 & 27 & 52.7 & 12.5 \\
\hline $\bar{\nabla}$ & & Spinal cord & 38.5 & 1.7 & 11.3 & 7.9 \\
\hline$\nabla$ & & Uner & 1031.4 & 1.6 & 98.2 & 18.0 \\
\hline $\bar{\Gamma}$ & & CTVT & 705.8 & 830 & 107.6 & 101.8 \\
\hline$\sqrt{2}$ & & PTVT & 9628 & 482 & 107.7 & 100.8 \\
\hline
\end{tabular}

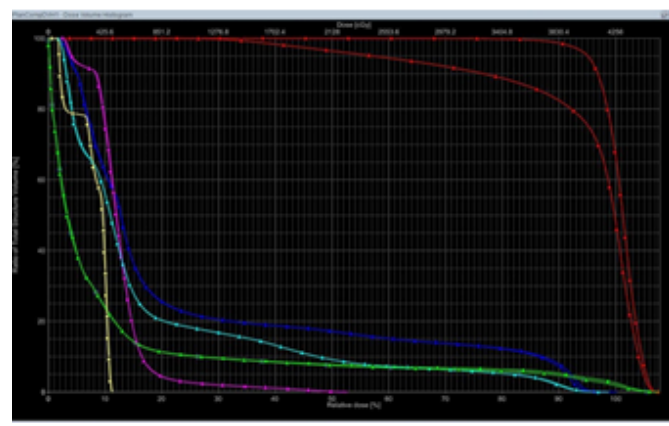

Fig.7. Comparative dose-volume histogram

Table 5

COMPARATIVE DOSE DISTRIBUTION

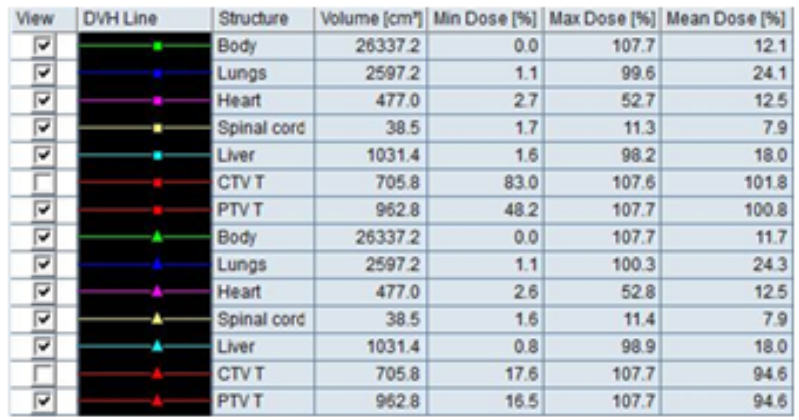

Following the analysis of the two treatment plans, the approved plan was the plan with the bolus. Figure 8 shows the position of the bolus on the right part of the treated patient's chest.

Checking the patient's treatment position and the bolus position on the skin (avoiding air gaps and for good reproductibility) was performed imagistically in the treatment room prior to irradiation (fig. 9).

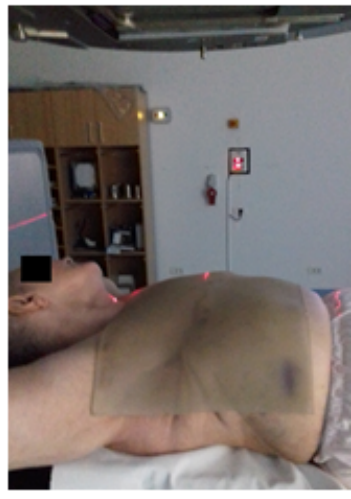

Fig.8. Pacient with bolus on the right chest wall

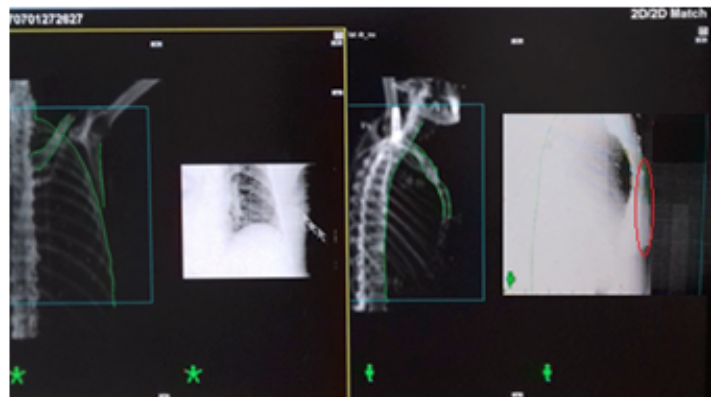

Fig.9. Imaging verification of the treatment position

\section{Conclusions}

Bolus materials are used during the high energy photon and electron radiation treatments of the different body areas (head and neck, chest wall, vulva) in order to deliver the full prescribed dose to the skin surface. Because of the risc from late atrophy associated with the bolus use, some radiation oncologists do not use the bolus or use it for only half of the number of fractions. Even if this late toxicity is 
possible, the benefit regarding PTV covering is higher and the use of bolus is recommended in the selected patients. The thickness of the applied bolus is dependent on the skin dose required, on the treatment technique and must be equal to the depth of the build-up region for the removal of the skin-sparing effect of a high energy radiation.

\section{References}

1.VU T.T., PIGNOL J.P., RAKOVITCH E., SPAYNE J., PASZAT L., Clin. Oncol. (R Coll Radiol), No. 19(2), 2007, p.115.

2.HEALY E., ANDERSON S., CUI J., BACKETT L., CHEN AM., PERKS J ., et al, Pract. Radiat. Oncol., No.3, 2013, p.45.

3. LUPASCU URSULESCU, C., URSARU, M., CIOBANU, D., NEGRU, D., LIUPASCU, C., Rev. Chim. (Bucharest), 68, no. 5, 2017, p. 1143

4. MUNTEANU, A., PATRASCU, A., FERARIU, D., Rev. Chim. (Bucharest), 68, no. 11, 2017, p. 2570
5. FILIP, C.I., BERBECE, S., RADUCU, L., FLORESCU, I.P., ARDELEANU, V., JECAN, C.R., Mat. Plast., 54, no. 3, 2017, p. 414

6.KUDCHADKER R. J ., ANTOLAK J. A., MORRISON W. H., WONG P. F., HOGSTROM K. R., J. OF APPL. CLIN. MED. PHYSICS, 4, No. 4, 2003, p.321.

7.HACKER N. F., EIFEL P. J., VAN DER VELDEN J., Int. J. of Gynecology and Obstetrics 119 S2, 2012, S90.

8.KIRKPATRICK J.P., DEMEHRI F.R., JOHNSTON S.E., STALNECKER A.M., COONEY T.M., Brevete US 20080123810, A1, 2008.

9.BOSTAN L., MUNTEANU F., POPA M.I., VERESTIUC L., Rev.Chim. (Bucharest), 61, no.12, 2010, p.1235.

10. CRETAN, M., GRIGORAS, S., HANGANU, L., STAMATE, C., HANGANU, S.C., MUNTEANU, F., Mat. Plast., 45, no. 1, 2008, p.109.

11.SHEN C., LINGYAN L., CHAO Z., JIE Z., Polymer, 51, No.23, 2010, p.5283.

Manuscript received: 2.11 .2016 